\title{
Ethical leadership and employee ethical behaviour: exploring dual-mediation paths of ethical climate and organisational justice: empirical study on Iraqi organisations
}

\author{
Hussam Al Halbusi ${ }^{*}$ \\ Department of Management, \\ College of Economics and Political Science, \\ Sultan Qaboos University, \\ P.O. Box 20, Al Khoud 123, Oman \\ Email: Hussam.mba@gmail.com \\ *Corresponding author
}

\section{Mohd Nazari Ismail and Safiah Binti Omar}

\author{
Department of Business Strategy and Policy, \\ Faculty of Business and Accountancy, \\ University of Malaya, \\ Petaling Jaya, 50603, Kuala Lumpur, Malaysia \\ Email: mdnazari@um.edu.my \\ Email:safiah@um.edu.my
}

\begin{abstract}
Due to ethical lapses of leaders, interest in ethical leadership has grown, raising important questions about the responsibility of leaders in ensuring moral and ethical conduct. Research conducted on ethical leadership failed to investigate the active role that the characteristics of ethical climate and organisational justice have an increasing or decreasing influence on the ethical leadership in the organisation's outcomes of employees' ethical behaviour. Thus, this study examined the dual-mediations of work ethical climate and organisational justice on the relation of ethical leadership and ethical behaviour of employees. A total of 620 full-time employees from five Iraqi provinces working at 33 Iraqi organisations in the field of manufacturing, retailing, medical, insurance, information technology, legal, finance, and telecommunication responded to the questionnaire survey. Structural equation modelling (SEM) was used to test the model and data analysis was carried out using structural equation modelling-partial least square (SEM-PLS). The results revealed that there is a significant relationship between ethical leadership behaviour and the ethical behaviour of employees. Primarily, the study also found that ethical climate and organisational justice play a very significant mediating role between ethical leadership and employees' ethical behaviour.
\end{abstract}

Keywords: ethical leadership; ethical climate; organisational justice; employees' ethical behaviour.

Reference to this paper should be made as follows: Al Halbusi, H., Bin Ismail, M.N. and Omar, S.B. (2021) 'Ethical leadership and employee ethical behaviour: exploring dual-mediation paths of ethical climate and organisational justice: empirical study on Iraqi organisations', Int. J. Business Governance and Ethics, Vol. 15, No. 3, pp.303-325. 
Biographical notes: Hussam Al Halbusi received his BSc in Business and administration and MSc in MBA From Fatih University, Turkey in 2015. He is currently pursuing his PhD degree at the University Malaya (UM), Malaysia. His research interests include business ethics, ethical leadership, corporate social responsibility (CSR) social cognitive theory, social learning theory social exchange theory and justice theory.

Mohd Nazari Ismail received his BSc (Hon) Economics, The University of Wales, Cardiff, UK, and MBA degree from the State University of New York, Buffalo. He received his $\mathrm{PhD}$ degree from the University of Manchester (UOM). He is currently a Professor at the Faculty of Business and Accountancy, Department of Business Strategy and Policy, University Malaya (UM).

Safiah Binti Omar received his BSc in Business Administration, Universiti Teknologi Mara (UITM), and BA Hons in Business Management, University of Sunderland. She received her Doctor of Philosophy in Business Management, Universiti Teknologi Mara (UITM) Malaysia. She is currently a Senior Lecturer at the Faculty of Business and Accountancy, Department of Business Strategy and Policy, University Malaya (UM).

\section{Introduction}

In recent years, ethical scandals and ethical behaviours have been of great concern to researchers, organisations, governments, and practitioners (Manz et al., 2008; Mehta, 2003; Brown and Trevinõ, 2006; Treviño et al., 2014; Al Halbusi and Tehseen, 2017; Babalola et al., 2019). The cause can be attributed to the various events which involved corporate ethical issues such as Enron, and the National Irish Bank. Padilla et al. (2007) and Schaubroeck et al. (2007) have noted that people with less ethical values tend to display more unethical behaviours and find opportunities to fulfil their personal desires, at the expense of others or their organisations. Arguments debating on how unethical behaviours affect immoral actions have been in existence since the beginning of civilisation (Treviño and Brown, 2004). However, nowadays the issue of ethical behaviour of employees is becoming a pressing worldwide issue. Moreover, it is also one of the most important and most frequent subjects of business ethics research since it is very critical and essential for organisations to implement socially responsible and ethical business practices. The subject of organisational behaviour is regarded as a function of an organisation's employees (Ones and Dilchert, 2012; Al Halbusi et al., 2019a). Employee responsible behaviours are individual-level employee actions that contribute to or detract from corporate social, ethical, and environmental performance. The establishment of ethical behaviours requires guidance and clear values and structures which is very critical to set up (Treviño et al., 2014; Al Halbusi et al., 2019a).

To prevent the occurrences of unethical behaviours and immoral actions taking place in the workplace, organisational leaders need to take strategic actions. Since the quality of the leadership has an impact on the organisation's moral and morale, many studies conducted by Brown and Treviño (2006), Neubert et al. (2009) and Brown and Treviño, (2014) questioned the role of ethical leadership in today's world. Clearly, a good leadership model needs to be emphasised consistently, and leaders need to be well 
selected so that subordinates can be better guided towards a better workplace environment. In any workplace, it is imperative that the institution or organisation be led by leaders of superior quality. Superior leaders need to display superior values and superior qualities, that is, they must possess high levels of ethical values, display ethical behaviours, and also apply the highest of ethical standards in their decision making, actions, and behaviours. Such a demonstration of leadership sets an ideal example for the followers (Ofori, 2009). Prior studies which focused on ethical leaderships have evidently stated that ethical leadership determines the ethical behaviours of the employees (Brown et al., 2005; Ofori, 2009; Al Halbusi et al., 2017; Neves et al., 2018; Fernández-de-Tejada et al., 2019).

In recent years, ethical leadership and employees' ethical behaviour have been widely discussed (Mayer et al., 2009; Lu and Lin 2014). In this context, not many studies have considered these relationships through mediations. For example, ethical climate and organisational justice may be important mediators on the relationship between ethical leadership and employees' ethical behaviour. Thus, this study argues that the inclusion of both organisational justice and work ethical climate in a single study may to some extent substitute each other in affecting employee ethical behaviour.

A study that considers this mediating will beneficial to today's work environment as the information gathered can contribute to the understanding of workplace behaviour as well as add to the theoretical debates in this area. The insights gathered will help managers to understand better what qualities are possessed by an ethical leader and what organisations can do to promote an ethical work climate and justice for the employees. Clearly, the employees' perception of work climate and fairness is important because it affects how employees treat themselves and others within the organisation, thereby, contributing to their future decision-making attitudes (Treviño et al., 2014). This study aims to expand on leadership literature as well as make a significant contribution by clarifying and understanding the relationship that exists between ethical leadership and ethical behaviour of employees through key mechanisms (i.e., ethical climate, organisational justice).

\subsection{Situational context}

Iraq is one of the places that are suffering from poor ethical behaviour in the Middle Eastern region (Spagat, 2010). The problem of this research arises from the reality of the social environment in Iraq. Based on anecdotal evidences many organisations in Iraq are lacking in when it comes to ethical issues. Public discussion are rife on the lack of ethical behaviour being the main contributing factor to the lack of effectiveness or even failures of organisations.

Moreover, the issue of business ethics in Iraq has been of increasing interest in recent years due to several reasons. Foremost of which are the increasing number of scandals involving corruption, abuse of power and favouritism, which are getting worse over the last two decades. As a result, there have been many conferences and symposiums held to discuss the matter and to identify the root cause of the problems (Arab and Atan, 2018; Al Halbusi et al., 2019a). Thus, the above is a reflection of the seriousness of the problems of ethics and corruption as perceived by the majority of Iraqi citizens (Agator, 2013; Al Halbusi et al., 2019b). Additionally, according to Khalil (2016), the main reason for the collapse of the Iraqi economy since April 2003 and the subsequent failure to 
develop is the misconduct of the employees as well as mismanagement by corrupt officials as well as the lack of engagement by the government in external and national programs. The lack of training to enhance and improve the ethical and responsible notion to the workers are complex and requires an in-depth understanding and effort. Furthermore, corruption and lack of ethical matters in the organisations and its form of processes for global developments in all intellectual, scientific and material fields have led to the weakness of international trust in Iraqi institutions, and the weakness of the Iraqi role in the economic activity and evolution action.

Thus, this study hopes to provide fresh evidence from a different perspective to enable increased understanding of the scope and type of misconduct affecting Iraqi organisations as well as to analyse the effectiveness of leadership and their employee's behaviour. In order to do so, new data, which focuses on the experience and the perception of ethical leadership, ethical climate, and organisational justice have been collected and analysed. Despite recent progress in the fight against misconduct and ethical scandals, much remains to be done to help establish integrity and accountability in the institutional sector of Iraq (Agator, 2013).

\section{Theoretical background and hypothesis development}

\subsection{Ethical leadership and ethical behaviour}

Ethical leadership comprises integrity, which is trustworthy and fair, shows concern for others, and behaves in an ethical way (Treviño et al., 2000; Mayer et al., 2009; Ofori, 2009). According to the studies of Treviño et al. (2000) and Brown et al. (2005) ethical leadership has been classified into dimensions:

1 moral personal factor which involves (i.e., integrity, concern for others, fair, and trustworthiness)

2 moral manager factor that consists (role modelling ethical conduct, determining ethical standards, punishing, communication and rewarding).

Therefore, as stated by Mayer et al. (2009) moral manager focuses more on transactional efforts to influence employees' ethical behaviour.

Khuntia and Suar (2004) argued that empowering and motivating subordinates should be encompassed as crucial elements of ethical leadership. Brown et al. (2005) identified the dimensions of ethical leadership, such as communication response, concerning a behaviour model, treating employees fairly, trustworthiness, and listening to employees. Moreover, ethical leadership dimensions should involve power-sharing, role clarification, and morality (De Hoogh and Den Hartog, 2008). Therefore, ethical leadership is a vital factor in ethical behaviour within an organisation (Stead et al., 1990; Mayer et al., 2009). Previously, it has been indicated that leaders represent an important organisational element that strongly influences employees' ethical behaviour (Stead et al., 1990; Brown et al., 2005; Treviño et al., 2014; Al Halbusi and Amir Hammad Hamid, 2018). Ethical manager comprises positive personal characteristics and seeks to influence their employees by actively managing ethical conduct. Ethical leadership displays regulated conduct in personal relationships within the organisation that is directed to strengthen and improve the ethical behaviour of employees. Socio-emotional exchange is one of the 
components which ethical leaders can have an impact on the subordinate (Mayer et al., 2009; Lu and Lin, 2014; Dimitriou and Ducette, 2018). Socio-emotional exchange is a behaviour that establishes trust and fairness between leaders and employees (Blau, 1964). When employees perceive that their leaders treat them fairly, they will believe that leader behaviour benefits the whole organisation, hence will less intend to behave in an unethical manner (Mayer et al., 2009; Treviño et al., 2014). Moreover, more empirical studies have indicated that ethical leadership has a significant effect on the ethical behaviour of employees (Dickson et al., 2001; Mayer et al., 2009; Brown et al., 2005; Ofori, 2009). More recently research has demonstrated that ethical leader has a critical role in influencing employees' ethical behaviour by daily communication with his/her followers (Brown et al., 2005; Lu and Lin, 2014; Neves et al., 2018; Moore et al., 2019). Employees' behaviour may change through the standards and guidance which were given by their leaders. Based on this argument, the research hypothesis has been developed.

H.1 Ethical leadership has a positive effect on the employee's ethical behaviour.

\subsection{Ethical climate as mediator}

The ethical climate has been defined as the "prevailing perceptions of typical organizational practices and procedures that have ethical content" (Victor and Cullen, 1988). Treviño et al. (1998) emphasised that in any organisation, ethical climate covers values and beliefs that conform to norms on moral issues that are shared between the employees of the organisation.

As has been cited previously, the ethical leader has a strong influence on employees' ethical behaviour. Mayer et al. (2009) and Brown and Treviño (2006) pointed out that ethical leadership is crucial in developing an ethical climate. In addition, there is empirical evidence to support that ethical leaders are critically influenced and developed an ethical climate (Dickson et al., 2001; Schminke et al., 2005; Mayer et al., 2009). Organisational leaders are capable of introducing ethical standards for an organisation based on procedures, policies, and processes that will aid employee's understanding of the organisation's ethical climate (Mayer et al., 2009; Schminke et al., 2005; Al Halbusi and Tehseen, 2018). The empirical research by Demirtas and Akdogan (2015) has constantly revealed that leader's moral is linked with the factors of ethical climate factor namely; organisation regulation, caring orientation, the orientation of the regulation and independent judgment. However, there are other studies that endorsed that ethical leadership has a crucial effect on the ethical climate (Mayer et al., 2009; Engelbrecht et al., 2005; Lu and Lin, 2014; Taştan and Davoudi, 2019).

Since the ethical climate is considered an important factor in influencing employee's behaviour, the reasons for using ethical climate as mediation in the present study are explained below. To facilitate employee's perceptions of the organisation's ethical climate, firstly an organisation decides on the ethical standards by implementing practices, policies, and processes as emphasised by management and how to deliver them to employees, that impact employees' perceptions of ethical climate. In practice, ethical climate takes into consideration 'what is the correct thing to do' that pertains to ethical norms, regularly communicating with subordinates on ethics and rewarding and punishing employees in accordance with ethical principles. In this manner, employees are fully aware of ethical climate standards and will uphold and abide by the organisational outcomes (Brown et al., 2005; Mayer et al., 2009). Secondly, as highlighted by Luria and 
Yagil (2008) the ethical climate is linked with the perception of trust, responsibility, and high moral standards on perceived righteousness and wrongfulness with the organisation. In addition, Jaramillo et al. (2005) commented that earlier studies have revealed that the unethical environment has disclosed that there are significant negative consequences in employees' behaviours within the organisations. To maintain the ethical behaviour of employees, the ethical climate is expected to enforce practices, policies, and processes. Thirdly, the ethical climate in the form of measures, processes, and policy is a warning to employees that doing the right thing is not only expected but is also encouraged and valued (Mayer et al., 2009). Meanwhile, the standards, practices, and procedures of ethical climate demonstrate to followers how to be skilful in identifying ethical issues and be equipped in handling ethical issues. Lu and Lin (2014) added that subordinates who heed such signals the perceived ethical climate are clear. Thus, it is essential to maintain high ethical standards without feeling the pressure to forego ethical conduct for the sake of achieving the business objectives in that instance, they are more likely to perform better behaviour.

Numerous empirical researches have endorsed that organisational leaders have influenced the ethical work environment. The relationship between leader moral and the organisation's ethical climate was studied by Schminke et al. (2005) and the results revealed that a leader's moral is associated with the ethical climate in organisations. In addition, Engelbrecht et al. (2005) pointed out that the consistency between ethical leaders is related to ethical climate. More recently, additional empirical researches have revealed that ethical leadership has a positive impact on the ethical climate (Neubert et al., 2009; Lu and Lin, 2014; Demirtas, 2015; Choi et al., 2015). The practice of role modelling appropriate behaviour may help ethical leaders enacting standards such as an ethical climate. By doing the right thing, employees perceive the procedures and policies of an organisation as an ethical climate, which in turn motivates them to show and perform better behaviour (Brown et al., 2005; Mayer et al., 2009; Lu and Lin 2014). In this study, we, therefore, examine these relationships by suggesting an ethical climate as a key mechanism between ethical leadership and the ethical behaviour of employees.

H.2 Ethical climate mediates the relationship between ethical leadership employees' ethical behaviour.

\subsection{Organisational justice as mediator}

Ethical leadership has contributed to the development of positive work behaviour among employees in the workplace, such as organisational commitment, performance and ethical behaviour of employees (Brown et al., 2005; Brown and Treviño, 2006). Fairness is the primary concern of ethical leaders as such this characteristic is conveyed to the employees by listening to their views and having clear and honest communication with their followers and also making the fair decisions (Neubert et al., 2009).

It is obvious that employees hugely care about how they are treated by others. Cropanzano and Greenberg (1997) and Angelidis and Ibrahim (2011) explained that organisational justice focuses on the perceptions of fairness in the workplace. Colquitt et al. (2001) declared that there are four components of organisational justice. The first component is distributive justice which pertains to equity theory as developed by Adams (1963). This component concerns the equal distribution of outcomes based on the performance of every individual employee (Steensma and Visser, 2007; Burney et al., 
2009). Procedural justice is the second component and was defined by Folger and Cropanzano (1998) and Cropanzano et al. (2001) as "neutrality, status (social position or status within a group or process) and trust procedural justice which was emphasized on the perceived fairness of the processes, i.e., procedures and policies used and their enactments of determining outcomes or resource distributions." The third component is interpersonal justice which Bies and Moag (1986) defined as "the quality of interpersonal treatment that they received during the enactment of organizational procedures and their interaction with leaders as they treated them with respect and dignity." The last component is informational justice which is the "process of receiving essential information in an appropriate manner and through clear communication" (Colquitt, 2001).

The current study proposed that organisational justice mediates the relationship between ethical leadership and employees' ethical behaviour. We consider organisational justice as a key mechanism for two reasons. Firstly, fairness is one of the most important characteristics of ethical leadership since ethical leaders display explicit fairness, honesty, and trustworthiness. Resulting from fair practice, employees working under this fair environment will very likely perceive the organisation's justice to be credible. Thus, employees will have the confidence to rely on the practice of fairness to eliminate any uncertainty about their relationship with their employer and behave ethically under this fair environment. On the contrary, employees who are treated unfairly and dishonestly would definitely observe an inconsistency in leadership behaviour and organisational justice. Under such situations, Brown et al. (2005) and Xu et al. (2016) emphasised that employees have the prerogative to question whether the fairness guidelines laid down are indeed reliable information which can help the workforce to anticipate a better future. It is very unlikely that the workforce will trust this organisational justice to start a relationship with their organisation should they find out that the fairness procedures are not adhered to. Lin et al. (2009) further explained that organisational justice is, therefore, an important and vital element that employees can use to infer how they are managed or treat by others.

Figure 1 Research model

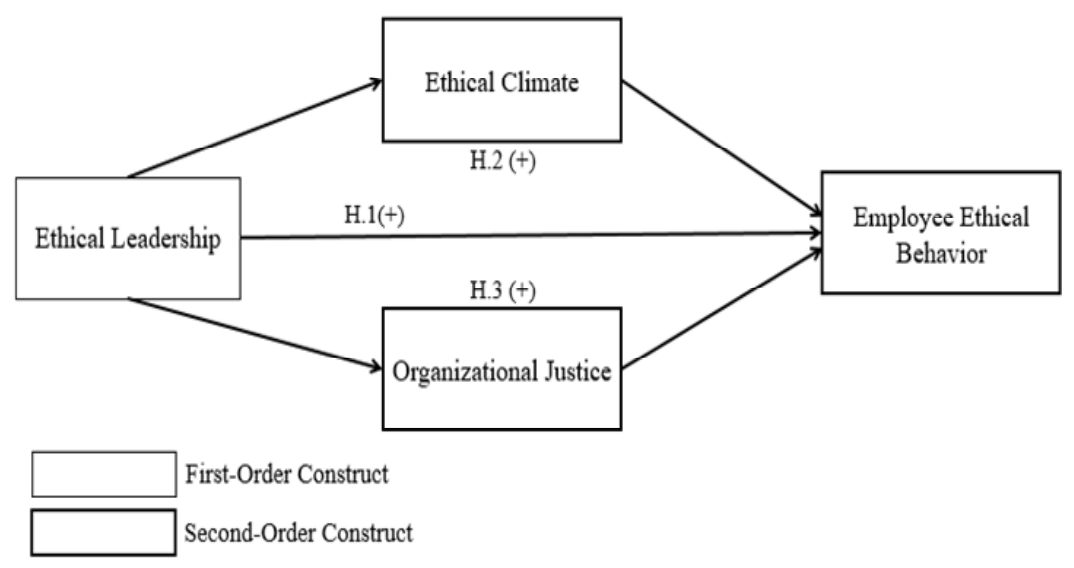

Secondly, organisational justice according to Colquitt and Greenberg (2003) and Brown et al. (2005) conveyed the expectations to employees with clear procedures, and 
distribution of what type of treatment the employees are expected to receive. Many in-depth studies have highlighted the need for systems and customs of the organisation to be made known to the employees. This is especially regarding the integrity of the organisation, such as making justice quite outstanding in the organisational context. In this way, employees will be inclined to accept that justice is not only important but is also the deciding factor whether an employee can continue to work in the organisation. In contrast, employees who are cynical and feel that there is unfairness and poor ethical standards in the organisation are unlikely to rely on organisational justice, thereby causing them to behave in an unethical manner to achieve their aims (Brown et al., 2005; Demirtas, 2015; Al Halbusi et al., 2018). Based on the above arguments, these relationships were further scrutinised by proposing organisational justice as a crucial mechanism in the relationship between ethical leadership and ethical behaviour of employees.

H.3 Perceived organisational justice mediates the relationship between ethical leadership and ethical behaviour of employees.

\section{Methodology}

\subsection{Sample and procedures}

The sample size developed for the current study was calculated using G-Power version 3.1 (Faul et al., 2007). According to Cohen (1992), the power of 0.95 (should be more than 0.80 , as required in social and behavioural science research) was considered as it has an effect size of 0.15 . Based on this, the minimum sample size required to test the model with three predictors is 77 .

In order to test the hypotheses, a sample size comprising 620 full-time employees working in 33, Iraqi organisations were approached. All the participants were directly affiliated with various industries such as manufacturing, retailing, medical, insurance, information technology, legal, finance, and telecommunication sectors coming from five Iraqi provinces. The criteria set for the selection was that the working experience of the respondents in the respective organisations should not be less than six months. The rationale is that this approach ensures that the samples accurately represent the population of interest. Since this study is the first of its kind in Iraq, it is extremely important to have an overview of the phenomenon in the context. To avoid any common method variance (CMV) in this study, we have employed procedural remedies which were carefully designed for the survey and used psychological and methodological separation. Also, we used statistical remedies by using 'cognitive rigidity' as marker variable to statistically detect any method bias (Podsakoff et al., 2003; Chin et al., 2013).

\subsection{Measurement}

In this study, since all the respondents speak Arabic, therefore, all the items in the questionnaires were translated from English to Arabic. Prior to translating to Arabic, the researchers ensured that the contents of the English version were accurate, understandable and acceptable. Subsequently, the questionnaire was translated according to the 'double-blinded principle' (Brislin, 1980) where the original English version was 
translated into Arabic, and the Arabic translated version was then translated back into English by two researchers who are familiar with the field of study to guarantee their validity. The questionnaire consists of four parts: ethical leadership; ethical climate organisational justice and ethical behaviour of employees. Both the English and Arabic versions of the surveys are presented in Appendix A and B respectively.

\subsubsection{Ethical leadership}

To measure ethical leadership, we adapted ten items, which were developed by Brown et al. (2005). The scale consists of ten items. An example item is, 'my supervisor listened to what employees have to say'. The response format is five-Likert scale ranging from ' 1 = strongly disagree' to ' 5 = strongly agree'.

\subsubsection{Ethical climate}

We measured ethical climate with fourteen items which were developed by Victor and Cullen (1988) thus, these items have been chosen for use in this survey. An example item is 'what is best for everyone in the organisation is the major consideration'. The response format is five-Likert scale ranging from ' $1=$ strongly disagree' to ' $5=$ strongly agree'.

\subsubsection{Organisational justice}

Organisational justice has been assessed by 20 items adapted from Colquitt's (2001) scale for employees' perception in the workplace. The 20 items refer to 'distributive justice', 'procedural justice', 'interpersonal justice' and 'informational justice'. The four types of equality pertaining to organisations are classified as follows: distributive justice was measured by using four items which concentrate more on equal payment, promotion, sufficient recognition, and rewards. A sample item is 'does your outcome reflect the effort you have put into your work'. Procedural justice, a seven-item scale was adapted for this variable. It measures the fairness procedures in the workplace and to what extent the procedures are equally and consistently applied to everyone. Sample items are 'have you been able to express your views and feelings during those procedures'. Interpersonal Justice was measured using a four-item scale regarding employees' interaction with their superior at the workplace such as how their supervisor treats them in a polite manner, with dignity, and with respect. A sample item is 'has your superior treated you in a polite manner'. For informational justice, the following five items refer to the authority figure who enacted the procedure in respect of the information being provided. The sample item is 'were your superior's explanations regarding the procedures reasonable'. All the response of organisational justice dimensions format is five-Likert scale with anchors of ' $1=$ to a small extent' to ' $5=$ to a large extent'.

\subsubsection{Ethical behaviour of employees}

In an organisation, the perceived ethical behaviour of employees is often referred to as ethical behaviour. Ferrell et al. (2000) and Lu and Lin (2014) pointed out that to measure this variable, sixteen items adapted from previous studies were used. Furthermore, ethical behaviour embraces two dimensions; normative ethical and juridical ethical behaviour. The norms of ethics are related activities; therefore, it is known as a normative ethical 
behaviour dimension. Whereas juridical ethical behaviour dimension is comprised of six items which are professional ethical related activities, the factor, hence it is identified as a juridical ethical behaviour dimension. Here is a sample of the items 'I am careful with company materials and supplies' and 'I refuse gifts that are offered for preferential treatment'. The response format is five-Likert scale ranging from ' $1=$ strongly disagree' to ' 5 = strongly agree'.

\subsubsection{Cognitive rigidity}

This variable was used as a 'marker variable' as this variable theoretically is not related to the research framework in this study. However, this variable has been used to statistically control the CMV. It contains three items, which were adapted from Lin et al. (2015) and Oreg (2003). The sample items are 'once I've come to a conclusion, I sometimes change my mind' and 'my views are very consistent over time'. Cognitive rigidity was replied on a five-point Likert scale ' $1=$ strongly disagree' to ' $5=$ strongly agree'.

\section{Data analysis and results}

In this study, structural equation modelling (SEM) using partial least squares (PLS) was conducted for the purpose of analysing the research model. The Smart-PLS 3.0 software was thus applied (Ringle et al., 2015). Researchers like Anderson and Gerbing (1988) and Hair et al. (2017), had recommended the need to apply two analytical techniques, starting with the assessment of the measurement model (validity and reliability), followed by the structural model assessment (hypothesis relationship testing). In this study, the two-step assessment approach was performed, involving both the measurement model and the structural model (Lomax and Schumacker, 2004). Hair et al. (2017) had also mentioned that the measurement model can indicate how each of the constructs measure. In order to explain the relationship between the variables, the structural model would be able to indicate how each of the constructs was related to each other. The PLS statistical method was chosen because the PLS possesses features that can simultaneously analyse the measurement model and the structural model, thereby giving a better and more accurate estimation (Barclay et al., 1995; Hair et al., 2017).

\subsection{Profile of respondents}

The SPSS version 23 was used to analyse the demographic information of the respondents which comprised of $75.6 \%$ males and $24.4 \%$ females, thus, indicating more men are involved in the industries. In terms of age, the majority or $42.6 \%$ catered to those between 31 and 40 years old. In terms of educational background, $54.8 \%$ have a bachelor's degree. In terms of job experience, the majority or $36.9 \%$ had six to ten years' work experience. In distinguishing the employees' type of organisation, the majority or $20.8 \%$ were from the insurance industry. Details are illustrated in Appendix C. 


\subsection{Common method variance}

As mentioned earlier, since it was difficult to collect data from multiple sources due to context complexities, the data used in this study were based on a self-reported questionnaire. Researchers like Podsakoff et al. (2003) and MacKenzie and Podsakoff $(2003,2012)$ had proposed numerous remedies for such an issue, such as minimising the likelihood of CMV bias by using both procedural and statistical remedies. Using procedural remedies, ensure the confidentiality and anonymity of the respondents by counterbalancing the order of the survey questions. The definitions for each of the constructs used were also provided. We also provided clear instructions to help respondents complete the evaluation of the items and we further used psychological separations throughout the measurement. In this study, we also applied statistical remedies (Podsakoff et al., 2003; Chin et al., 2013) like 'cognitive rigidity' to be used as the 'marker variable' so as to statistically control the method bias. This variable was theoretically unrelated to the research model, but we used it as a remedial step.

Statistical remedies were applied as control (CMV), and two approaches were recommended by Chin et al. (2013) and Tehseen et al. (2017) to detect the impact of the CMV. The first approach was the construct level correction (CLC) while the second approach was the item level correction (ILC). However, this study was only concerned with the CLC. Therefore, to test the common method bias, several steps need to be followed. First, we drew and ran the hypothesised model by using the Smart PLS software. Thus, we run the model without the 'marker variable' then we observed the path coefficient value, then the path coefficients are again estimated after introducing CMV control constructs on the models' constructs. Hence, it was observed that the original estimated path coefficient of ethical leadership is 0.216 and the path coefficient estimated by CLC is 0.203 . On the other hand, the original estimated path coefficient of the ethical climate is 0.645 and the path coefficient estimated by CLC is 0.650 . The original estimated path coefficient of organisational justice is 0.653 , and the path coefficient estimated by CLC is 0.651 . Similarly, there were no-significant changes in other parameters as well. For example, t-values of ethical leadership, ethical climate, and organisational justice are 5.020,6.480, and 4.433, respectively in the original PLS model. On the other hand, the t-values of ethical leadership, ethical climate and organisational justice estimated by the CLC approach are 4.856, 6.478, and 4.430, respectively. Thus, these changes are very small and are not significant, therefore, based on these changes it can be concluded that CMV is not an issue in this study (see Table 1).

Table 1 Comparison of path coefficients and t-values by original PLS models and CLC approach

\begin{tabular}{lcccc}
\hline \multirow{2}{*}{ Relationships } & $\begin{array}{c}\text { Original } \\
\text { estimates }\end{array}$ & CLC estimation & $\begin{array}{c}\text { Original } \\
\text { estimates }\end{array}$ & CLC estimation \\
\cline { 2 - 5 } & Path coefficients & Path coefficients & $t$-value & $t$-value \\
\hline EL -> EB & 0.216 & 0.203 & 5.020 & 4.856 \\
EL -> EC & 0.645 & 0.650 & 6.480 & 6.478 \\
EL -> OJ & 0.653 & 0.651 & 4.433 & 4.430 \\
\hline
\end{tabular}

Notes: EL -> EB ethical leadership and ethical behaviour, EL $->$ EC ethical leadership and ethical climate and EL -> OJ ethical leadership and organisational justice. 


\subsection{Measurement model assessment}

The measurement model was assessed using both construct reliability and construct validity (including convergent and discriminant validity). For construct reliability, the individual Cronbach's alpha to measure the reliability of each of the core variables in the measurement model was tested in this study. Nunnally and Bernstein, (1994) and Hair et al. (2017) revealed that all the individual Cronbach's alpha ranging from $(0.725$ to 0.926) were higher than the suggested value of 0.7 . In addition, this study engaged the composite reliability (CR) to test the construct reliability which achieved the proposed values. According to Hair et al. (2017) the values ranging from 0.850 to 0.935 were higher than 0.7 which perfectly indicated that the construct reliability is fulfilled as shown in Appendix D. Therefore, the achieved Cronbach's alpha and CR for all constructs were deemed to be error-free. A factor loading test was carried out to gauge the indicator reliability. When a construct has high loading, it shows that the associated indicators have much in common which is captured by the construct (Hair et al., 2017). It is shown in Appendix D, that the loadings for all items exceeded the recommended value of 0.5 except for item EC6 and EEB9 which were removed from the scale due to low loadings. It is noted that the loading for the remaining items in the model has fulfilled all the requirements.

Testing the convergent validity, using the average variance extracted (AVE) is to gauge the extent to which a measure correlates positively with alternative measures of the same construct. Proof of the convergent validity was confirmed because the AVE for all the constructs exceeded the threshold which ranged from 0.513 to 0.883 according to Hair et al. (2017) which is presented in a measurement model (refer to Appendix D).

There are two criteria when assessing discriminant validity:

1 Fornell-Larcker

2 HTMT.

In recent works of literature, the criterion of Fornell-Larcker has been strongly criticised as it has failed to accurately reveal the lack of discriminant validity in common research situations (Henseler et al., 2015). Alternatively, it was suggested to use the technique, Heterotrait-Monotrait ratio (HTMT) of correlations and based it on the multitrait-multimethod matrix. Hence, in this study, HTMT was employed to assess discriminant validity. A problem exists with the discriminant validity when the HTMT value is greater than the HTMT0.85 value of 0.85 (Kline, 2010), as revealed in Table 2 which indicates that the determined discriminant validity was lower than the recommended values.

Table 2 Discriminant validity via the HTMT criterion

\begin{tabular}{lcccc}
\hline Constructs & $E B$ & $E C$ & $E L$ & $O J$ \\
\hline EB & & & \\
EC & 0.790 & & \\
EL & 0.683 & 0.691 & & \\
OJ & 0.673 & 0.816 & 0.666 & \\
\hline
\end{tabular}

Notes: HTMT; value should be less than 0.85 . EB: ethical behaviour, EC: ethical climate, EL: ethical leadership and OJ: organisational justice. 
Table 3 Path coefficients (direct effect) and (indirect effect)

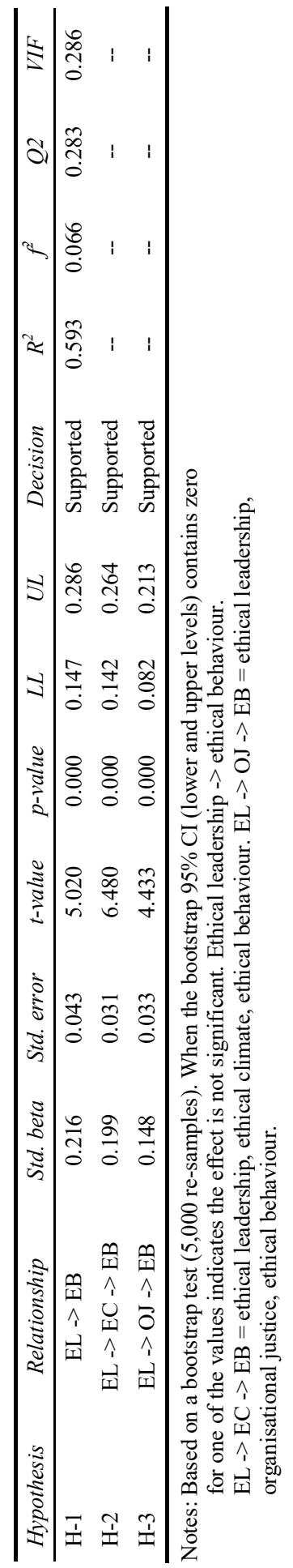




\subsection{Assessment of the structural model}

The criteria for structural model assessment was proposed by Hair et al. (2017) This criterion can be assessed by looking at the latent collinearity issue, the beta $(\beta), \mathrm{R}^{2}$ and the corresponding t-values through the bootstrapping process with re-sampling of 5,000. The effect size $\left(\mathrm{f}^{2}\right)$ needs to be reported also as was suggested. In addition, Sullivan and Feinn (2012) cited that the p-value can be applied to establish whether the effect exists, but in this way, it will not disclose the size of the effect.

\subsection{Hypothesis testing}

Hair et al. (2014) and Wetzels et al. (2009) proposed that the research hypothesis be examined using the structural model and the level of acceptance of the path coefficients in order that the 0.1 path coefficient will have an impact on the model. Also, it is suggested that a significant level of the coefficients be at least 0.05 (i.e., $95 \%$ confidence level). The effectiveness of the hypotheses for all constructs was based on the t-values taken from Smart-PLS bootstrapping from the 5,000 samples. This research recommended the positive association of ethical leadership and the ethical behaviour of employees. This was accomplished by comparing the t-values using a one-tailed test to test the significance as shown in Table 3. The results revealed that $\mathrm{H} 1$ ethical leadership on the employees ethical behaviour was supported $(\beta=0.216, \mathrm{t}=5.020 ; \mathrm{p}<0.000)$. Refer to Table 3.

Hair et al. (2017) proposed to test the mediating effect of ethical climate and organisational justice on the relationship of ethical leadership and ethical behaviour of employees by adopting the bootstrapping method formulated by Preacher and Hayes $(2004,2008)$. The outcome of the analysis, presented in Table 3 , revealed that the indirect effect of the ethical climate was significant with $(\beta=0.199$, $t$-value $6.480, p<0.000)$. Organisational justice was also found to be significant with $(\beta=0.148$, t-value 4.433 , $\mathrm{p}<0.000)$. Preacher and Hayes (2008) commented when the 0.199 , 95\%, CI: $[\mathrm{LL}=0.142, \mathrm{UL}=0.264]$ as well as $0.148,95 \%, \mathrm{CI}$ : $[\mathrm{LL}=0.082, \mathrm{UL}=0.213]$ does not straddle a 0 in between, mediation is thus indicated. Therefore, in this study, we can conclude that the mediation effect of ethical climate and organisational justice is statistically significant. Hence, $\mathrm{H} 2$ and $\mathrm{H} 3$ are supported.

In terms of the explanatory power of the model, the $\mathrm{R}^{2}$ and Q2 (predictive relevance of the endogenous variable) offered more than satisfactory values. First, the model explains $\mathrm{R}^{2}$ values of 0.593 for the dependent variable, thus involving a moderate explanatory power (Hair et al., 2017). Also, the Stone-Geisser blindfolding sample reuse technique, with an omission distance of 7 , reveals good predictive relevance for the model in predicting employee's ethical behaviour, as this value is far larger than zero $(\mathrm{Q} 2=0.283)$ (Hair et al., 2017).

\section{Discussion and conclusions}

Treviño et al., (2014) and Bright et al. (2014) mentioned that ethics as the standards, norms, and values that control the behaviour of individuals. In our society, human beings value the importance of ethical behaviour as we all want to be treated with respect. In the earlier studies, the antecedents of the ethical behaviour of employees were examined to 
identify those factors that would improve ethical behaviour in an organisation as well as enhance the relationship between leaders and their subordinates (Brown et al., 2005; Mayer et al., 2009). Thus, in this study, we investigated the relationship between the ethical leadership behaviour and ethical behaviour of employees through ethical climate and organisational justice as mediators.

The success of an organisation depends on the primary resources of managers as revealed in this study that employees' ethical behaviour is significantly influenced by ethical leadership. Also, it was debated that role models in an organisation can achieve moral authority that has a virtuous influence on organisational members' behaviour. This can be attained by exhibiting ethical leadership behaviour and producing relevant attachments. In addition, there are several other important factors that can be drawn from the findings of this study. Firstly; Iraqi organisations must seriously consider the significant factor which has a major influence on the ethical behaviour of employees. Hence, Iraqi businesses should endeavour to choose and/or educate ethical leaders bearing in mind the benefits of ethical leadership by increasing employees' ethical behaviour. However, there are options available to organisations, e.g., by hiring more ethical leaders and providing training to existing leaders. Suitable topics for training could cover the importance of ethics, rewards and supporting employees who behave ethically and serve as ethical behaviour role models. The findings of this study were similar to the study by Brown and Treviño (2006), Demirtas (2015), Lu and Lin (2014) and Mayer et al. (2009).

As referred to earlier, the behaviour on ethical leadership was tested against employees' ethical behaviour. The statistical results firstly; revealed that there is a significant relationship between ethical leadership and the ethical behaviour of employees. Secondly; it was established that ethical climate and organisational justice had a significant mediating role in the relationship between ethical leadership and employees' ethical behaviour.

On the work ethical climate, Victor and Cullen (1988) defined it as the "predominant perceptions about the procedures and practices of the organization that has ethical content or the prevailing perceptions of typical organizational practices and procedures that have ethical content." In order to exhibit ethical behaviour depends on multifactorial entities the behaviour of managers is generally reckoned as the most important and influential factor in creating ethical behaviour of employees which is the main focus of this study. Several studies conducted by Brown et al. (2005), Engelbrecht et al. (2005), Lu and Lin (2014) and Mayer et al. (2009) had established that ethical leadership has strongly influenced ethical climate which in turn ethical climate has an important role in shaping employees' ethical behaviour. Also, the findings have proven that there is value in creating an ethical climate within the workplace since there is a positive association between ethical climate and employees' ethical behaviour. An organisation who desires to increase ethical conduct should recruit leaders who can encourage and introduce ethical behaviour and systems that reward ethical behaviour and discipline unethical conduct. This study further proposed that Iraqi companies who want to promote the good ethical behaviour of its employees should strictly adhere to the law and professional standards and public rather than self-interest (Treviño et al., 1998). Another aspect of the finding discovered that managers who exhibit ethical leadership qualities, such as integrity and fairness, who reward and support employees and who behave ethically, emphasising on ethical standards and service as ethical behaviour role models, are in a 
better position to create an ethical climate as doing the right thing is value. Mayer et al. (2009) and Treviño et al. (2014) highlighted that when employees operate in an ethical climate, the chances they are more likely to engage in ethical behaviour. An analysis of this study, further revealed that in the Iraqi context, leaders could increase ethical behaviour among employees. This could be accomplished by improving the ethical climate and enacting ethical rules and standards and by displaying the highest ethical behaviour within the organisation and setting very clear ethical standards. Basically, the relationship between ethical leadership and employees' ethical behaviour is mediated by ethical climate.

A second mediation testing of organisational justice was carried out between ethical leadership behaviour and the ethical behaviour of employees. The results also indicated that organisational justice significantly mediated the relationship between ethical leadership and employees' ethical behaviour. Relying on the extended literature on business ethics, this study has helped to improve the understanding of the role of ethical leadership, organisational justice, and ethical behaviour. According to Colquitt et al. (2001) literature and organisational justice can be defined as "the subjective perception of people of fairness in organizations." The significant mediating role of organisational justice on the relationship of ethical leadership and employees' ethical behaviour was substantiated by the statistical results of this study. Additionally, the influence of ethical leadership on individual behaviour was also investigated. By shaping organisational justice, ethical leadership behaviour can influence the ethical behaviour of employees. Leaders who are viewed as ethical by their subordinates are in a good position to increase the organisational justice perception which will ultimately influence ethical behaviour.

It has been predicted by certain outcomes such as ethical conduct the basic value of understanding ethical leadership. As noted earlier, employees' justice perceptions affect their behaviour and interactions at work. Treviño et al. (2014) commented that people perceive the quality of their organisation as an indication of a more positive impact for the followers. Basically, these relationships are the notions of fairness and reciprocity, but it was contended by Colquitt et al. (2001) that people have a criterion for fairness perceptions within a social exchange relationship. It is likely people will assume there is a social exchange relationship with their supervisor or organisation unless such a relationship does not exist due to unfairness. However, if unfair judgments arise during social exchanges, this will create a negative effect on organisations such as unethical behaviour. Brown and Treviño (2006) stressed that those who accept organisational decisions tend to cooperate with the organisations. Also, employees will apply their experience adopting fair or unfair allocation procedures as information reflects on the organisation as a whole. It is envisaged that employees who are endowed with proper treatment in terms of equity and quality of distribution, procedures and high-quality interpersonal relationships and clear communication will undoubtedly improve their ethical behaviour. This will convince them to improve their exchange relationship with the manager, who in turn is directed to increase the ethical behaviour. Although the exchange relationship between manager and employee is deemed one of the influential factors towards the followers, nevertheless, fairness is considered as one of the most substantial characteristics of the ethical leader. In view of this, ethical leadership affects the employees' perceptions of fairness and this perception of fairness will incite employees to reciprocate with their work-related outcomes. Thus, as a result, this study has revealed that in the Iraqi context, leaders could increase the ethical behaviour among employees by improving the organisational justice perception by enactment, procedural, 
distributive, rules, and reasonable process and by displaying fair treatment. In essence, organisational justice mediates the relationship between ethical leadership and employees' ethical behaviour. Therefore, Iraqi organisations should pay attention to and be concerned and promoting their managers in order to establish organisational justice.

\subsection{Theoretical implication}

Frisch and Huppenbauer (2014) and Mitchell et al. (2017), pointed out that there is limited research in the area of the ethical leadership behaviour as not many studies in ethical behaviour were included previously. To be more precise, previous research only focused on ethical leadership behaviour to influence the organisation's outcomes such as commitment, work engagement, and satisfaction. Specifically, research on the ethical behaviour of employees has been neglected by previous studies. Therefore, this study examines the relationship between ethical leadership behaviour and employees' ethical behaviour.

The current study contributes to the new model by determining the new relationship through the mediating role of ethical climate and organisational justice on the interaction of ethical leadership behaviour and the dependent variable of employees' ethical behaviour. More precisely, the present study made a very significant contribution to the existing literature. First, this study contributes by expanding the set of positive outcomes that are expected through ethical leadership, ethical climate and organisational justice perceptions among employees. Most of the existing research has examined the relationship between ethical leadership perceptions and different types of positive responses (i.e., organisational commitment, job satisfaction, work performance, and organisational citizenship behaviours) (Treviño et al., 2014). Very few studies have addressed the influence of ethical leadership towards employees' ethical behaviour through the mediating role such as ethical climate and organisational justice. Therefore, the current study suggested that ethical climate and organisational justice may constitute each other and play a significant role on the relation of ethical leadership and employees' ethical behaviour (Treviño et al., 2014), and the majority of these studies have focused on western cultural contexts (McCain et al., 2010; Treviño and Weaver, 2001). Thus, by finding how ethical leadership positively influence ethical behaviour through mediating role of ethical climate and organisational justice, in a Middle Eastern country like Iraq, this study is an important step forward to generalise the truth of these relationships across different cultural contexts.

\subsection{Managerial implication}

This study is important for ethical leadership behaviour which is related to ethical behaviour in Iraqi organisations. The results of this study provide instructions for building a better-quality relationship between leaders and subordinates in an organisational context. The results of this study provide guidelines on how the quality of the manager can provide and improve the perceptions of ethical climate, justice in an organisational context.

Furthermore, as practical implications, this study finds that ethical leadership has a positive effect on the ethical behaviour of employees, which further increases employee ethical behaviour. Prior studies have suggested that top managers, in particular, the chief 
executive officer could shape the ethical climate and organisational justice which further affects employee behaviour (Chun et al., 2013). In addition, this study provides some viable way for top managers to achieve that. Specifically, top managers may use to signal their ethical values to subordinates, motivating them to adopt ethical standards. Moreover, this study also suggests that organisational equity and work ethical climate may to some extent substitute each other in affecting employee ethical behaviour. Thus, firms with a low level of ethical climate and justice at least from the point of view of employees should be in a better position to conduct ethical leadership to build an ethical climate and justice. Most importantly, in terms of management, the findings send a clear signal to upper levels, without ignoring the issues of ethics in organisations which has to do with many other questions then the role of leadership, work climate and justice. Failing to make ethical standards in the organisation and be perceived by the employees is also a critical aspect to be taken into account to encourage workplace ethical behaviour.

The present findings suggest that there can be constraints influencing (by augmenting or buffering) the positive effects that establish work climate and justice criteria in the outcomes provided to employees and the procedures used to make decisions are expected to bring through social exchange processes. Indeed, based on social exchange processes, organisational climate and justice perceptions can activate in employees' positive responses, including ethical behaviour. However, even if the organisations do all that is necessary to guarantee ethical outcomes and processes in the organisation, employees may react to these aspects differently. Ethical leadership has a clear and contingent role to effect on the ethical behaviour of employees. Therefore, the upper echelons must understand the role of the leader prior to knowing how organisational climate and justice will affect the ethical behaviour of these employees and complement the managerial actions implemented with others that allow ensuring ethical workplace behaviour.

\subsection{Conclusions}

The objective of this research was to investigate the relationship between ethical leadership and ethical behaviour of employees. Also, to examine the mediating role of ethical climate and organisational justice on the relationship of ethical leadership (IV) and employees' ethical behaviour (DV) among Iraqi organisations. In addition, we believe this research provides insight into the important relationship between ethical leadership and its effect on employees' ethical behaviour by shaping ethical climate organisational justice. Thus, we found that ethical leadership significantly influenced employees' ethical behaviour. Importantly, this study revealed that ethical climate and organisational justice significantly mediated the relationship between ethical leadership and employees' ethical behaviour.

Appendices/Supplementary materials are available on request by emailing the corresponding author or can be obtained under http://eprints.um.edu.my/id/eprint/24118. 


\section{References}

Adams, J.S. (1963) 'Towards an understanding of inequity', The Journal of Abnormal and Social Psychology, Vol. 67, No. 5, p.422.

Agator, M. (2013) Overview of Corruption and Anti-Corruption [online] https://www.u4.no/ publications/iraq-overview-of-corruption-and-anti-corruption (accessed February 2019).

Al Halbusi, H. and Amir Hammad Hamid, F. (2018) 'Antecedents influence turnover intention: theory extension', Journal of Organizational Behavior Research, Vol. 3, No. 2, pp.287-304.

Al Halbusi, H. and Tehseen, S. (2017) 'Corporate social responsibility (CSR): a literature review', Malaysian Journal of Business and Economics, Vol. 4, No. 2, pp.30-48.

Al Halbusi, H. and Tehseen, S. (2018) 'Impact of ethical leadership on affective commitment through mediating impact of ethical climate: a conceptual study', Durreesamin Journal, Vol. 4, No. 2, pp.1-14.

Al Halbusi, H., Ismail, M.N. and Omar, S. (2019a) 'Examining the impact of ethical leadership on employees 'ethical behavior: the role of organizational justice and employees 'moral identity', Journal of Technology Management and Business, Vol. 6, No. 2, pp.1-19.

Al Halbusi, H., Ismail, M.N.B. and Omar, S.B. (2019b) 'A conceptual proposal: ethical leadership moderates the effect of organizational justice on ethical employee behavior', Kuwait Chapter of the Arabian Journal of Business and Management Review, Vol. 8, No. 1, pp.10-19.

Al Halbusi, H., Williams, K.A., Mansoor, H.O., Hassan, M.S. and Hamid, F.A.H. (2019c) 'Examining the impact of ethical leadership and organizational justice on employees' ethical behavior: does person-organization fit play a role?', Ethics \& Behavior, Vol. 29, pp.1-19.

Al Halbusi, H., Tehseen, S. and Ramayah, T. (2017) 'The impact of organizational justice on the ethical leadership under the moderating influence of perceived support: a conceptual study', Malaysian Journal of Business and Economics, Vol. 4, No. 1, pp.46-64.

Al Halbusi, H., Tehseen, S., Hamid, F.A.H. and Afthanorhan, A. (2018) 'A study of organizational justice on the trust in organization under the mediating role of ethical leadership', Business Ethics and Leadership, Vol. 2, No. 4, pp.1-10.

Anderson, J.C. and Gerbing, D.W. (1988) 'Structural equation modeling in practice: a review and recommended two-step approach', Psychological Bulletin, Vol. 103, No. 3, p.411.

Angelidis, J. and Ibrahim, N.A. (2011) 'The impact of emotional intelligence on the ethical judgment of managers', Journal of Business Ethics, Vol. 99, No. 1, pp.111-119.

Arab, H.R. and Atan, T. (2018) 'Organizational justice and work outcomes in the Kurdistan Region of Iraq', Management Decision, Vol. 56, No. 4, pp.808-827.

Babalola, M.T., Stouten, J., Camps, J. and Euwema, M. (2019) 'When do ethical leaders become less effective? The moderating role of perceived leader ethical conviction on employee discretionary reactions to ethical leadership', Journal of Business Ethics, Vol. 154, No. 1, pp.85-102.

Barclay, D., Higgins, C. and Thompson, R. (1995) 'The partial least squares (PLS): approach to causal modeling: personal computer adoption and use as an illustration', Technology Studies, Vol. 2, pp.285-309.

Bies, R. and Moag, R. (1986) 'Interactional justice: communication criteria of fairness', in Lewicki, R.J., Sheppard, B.H. and Bazerman, M.H. (Eds.): Research on Negotiations in Organizations, pp.43-55, 1JAI Press, Greenwich.

Blau, P. (1964) Exchange and Power in Social Life, Department of Sociology, University of Chicago, Routledge. New York: Wiley, 352pp.

Bright, D.S., Winn, B.A. and Kanov, J. (2014) 'Reconsidering virtue: differences of perspective in virtue ethics and the positive social sciences', Journal of Business Ethics, Vol. 119, No. 4, pp.445-460.

Brislin, R.W. (1980) 'Translation and content analysis of oral and written materials', in Triandis, H.C. and Berry, J.W. (Eds.): Handbook of Cross-Cultural Psychology: Methodology, pp.389-444, Allyn \& Bacon, Boston. 
Brown, M.E. and Treviño, L.K. (2006) 'Ethical leadership: a review and future directions', The Leadership Quarterly, Vol. 17, No. 6, pp.595-616.

Brown, M.E. and Treviño, L.K. (2014) 'Do role models matter? An investigation of role modeling as an antecedent of perceived ethical leadership', Journal of Business Ethics, Vol. 122, No. 4, pp.587-598.

Brown, M.E., Treviño, L.K. and Harrison, D.A. (2005) 'Ethical leadership: a social learning perspective for construct development and testing', Organizational Behavior and Human Decision Processes, Vol. 97, No. 2, pp.117-134.

Burney, L.L., Henle, C.A. and Widener, S.K. (2009) 'A path model examining the relations among strategic performance measurement system characteristics, organizational justice, and extra-and in-role performance', Accounting, Organizations and Society, Vol. 34, No. 3, pp.305-321.

Chin, W.W., Thatcher, J.B., Wright, R.T. and Steel, D. (2013) Controlling for Common Method Variance in PLS Analysis: the Measured Latent Marker Variable Approach New Perspectives in Partial Least Squares and Related Methods, pp.231-239, Springer, New York, NY.

Choi, S.B., Ullah, S. and Kwak, W.J. (2015) 'Ethical leadership and followers' attitudes toward corporate social responsibility: the role of perceived ethical work climate', Social Behavior and Personality: An International Journal, Vol. 43, No. 3, pp.353-365.

Chun, J.S., Shin, Y., Choi, J.N. and Kim, M.S. (2013) 'How does corporate ethics contribute to firm financial performance? The mediating role of collective organizational commitment and organizational citizenship behavior', Journal of Management, Vol. 39, No. 4, pp.853-877.

Cohen, J. (1992) 'Statistical power analysis', Current Directions in Psychological Sciences, Vol. 1, No. 3, pp.98-101.

Colquitt, J.A. (2001) 'On the dimensionality of organizational justice: a construct validation of a measure', Journal of Applied Psychology, Vol. 86, No. 3, p.386.

Colquitt, J.A. and Greenberg, J. (2003) 'Organizational justice: a fair assessment of the state of the literature', in Greenberg, J. (Ed.): Organizational Behavior: The State of the Science, pp.165-210, Lawrence Erlbaum Associate, Inc., Mahwah.

Colquitt, J.A., Conlon, D.E., Wesson, M.J., Porter, C.O. and Ng, K.Y. (2001) 'Justice at the millennium: a meta-analytic review of 25 years of organizational justice research', Journal of Applied Psychology, Vol. 86, No. 3, p.425.

Cropanzano, R. and Greenberg, J. (1997) 'Progress in organizational justice: tunneling through the maze', International Review of Industrial and Organizational Psychology, Vol. 12, pp.317-372.

Cropanzano, R., Byrne, Z.S., Bobocel, D.R. and Rupp, D.E. (2001) 'Moral virtues, fairness heuristics, social entities, and other denizens of organizational justice', Journal of Vocational Behavior, Vol. 58, No. 2, pp.164-209.

De Hoogh, A.H. and Den Hartog, D.N. (2008) 'Ethical and despotic leadership, relationships with leader's social responsibility, top management team effectiveness and subordinates' optimism: a multi-method study', The Leadership Quarterly, Vol. 19, No. 3, pp.297-311.

Demirtas, O. (2015) 'Ethical leadership influence at organizations: evidence from the field', Journal of Business Ethics, Vol. 126, No. 2, pp.273-284.

Demirtas, O. and Akdogan, A.A. (2015) 'The effect of ethical leadership behavior on ethical climate, turnover intention, and affective commitment', Journal of Business Ethics, Vol. 130, No. 1, pp.59-67.

Dickson, M.W., Smith, D.B., Grojean, M.W. and Ehrhart, M. (2001) 'An organizational climate regarding ethics: the outcome of leader values and the practices that reflect them', The Leadership Quarterly, Vol. 12, No. 2, pp.197-217.

Dimitriou, C.K. and Ducette, J.P. (2018) 'An analysis of the key determinants of hotel employees' ethical behavior', Journal of Hospitality and Tourism Management, Vol. 34, pp.66-74. 
Engelbrecht, A.S., Van Aswegen, A.S. and Theron, C.C. (2005) 'The effect of ethical values on transformational leadership and ethical climate in organizations', South African Journal of Business Management, Vol. 36, No. 2, pp.19-26.

Faul, F., Erdfelder, E., Lang, A.G. and Buchner, A. (2007) 'G* Power 3: a flexible statistical power analysis program for the social, behavioral, and biomedical sciences', Behavior Research Methods, Vol. 39, No. 2, pp.175-191.

Fernández-de-Tejada, V., Palencia-González, F.J., Saavedra, I. and Solórzano-García, M. (2019) 'Is ethical management of human resources inherent to social enterprises? European tradition model versus Anglo-Saxon model', International Journal of Business Governance and Ethics, Vol. 13, No. 4, pp.385-407.

Ferrell, O.C., Fraedrich, J. and Ferrell, L. (2000) Business Ethics: Ethical Decision Making and Cases, 4th ed., Houghton Mifflin Inc., New York.

Folger, R.G. and Cropanzano, R. (1998) Organizational Justice and Human Resource Management, Vol. 7, Sage, Thousand Oaks.

Frisch, C. and Huppenbauer, M. (2014) 'New insights into ethical leadership: a qualitative investigation of the experiences of executive ethical leaders', Journal of Business Ethics, Vol. 123, No. 1, pp.23-43.

Hair Jr., J., Sarstedt, M., Hopkins, L. and Kuppelwieser, V.G. (2014) 'Partial least squares structural equation modeling (PLS-SEM) an emerging tool in business research', European Business Review, Vol. 26, No. 2, pp.106-121.

Hair, J.F., Hult, G.T.M., Ringle, C. and Sarstedt, M. (2017) A Primeron Partial Least Squares Structural Equation Modeling (PLS-SEM), 2nd ed., SAGE, Thousand Oaks, London.

Henseler, J., Ringle, C.M. and Sarstedt, M. (2015) 'A new criterion for assessing discriminant validity in variance-based structural equation modeling', Journal of the Academy of Marketing Science, Vol. 43, No. 1, pp.115-135.

Jaramillo, F., Mulki, J.P. and Marshall, G.W. (2005) 'A meta-analysis of the relationship between organizational commitment and salesperson job performance: 25 years of research', Journal of Business Research, Vol. 58, No. 6, pp.705-714.

Khalil, S. (2016) The Reality of the Institutes System in Iraq, Rawabet Center for Research and Strategic Studies [online] http://rawabetcenter.com/en/?p=1434 (accessed 15 June 2019).

Khuntia, R. and Suar, D. (2004) 'A scale to assess ethical leadership of Indian private and public sector managers', Journal of Business Ethics, Vol. 49, No. 1, pp.13-26.

Kline, R.B. (2010) Principles and Practice of Structural Equation Modeling, 3rd ed., The Guilford Press, New York.

Lin, T-C., Huang, S-L. and Hsu, C-J. (2015) 'A dual-factor model of loyalty to IT product the case of smartphones', International Journal of Information Management, Vol. 35, No. 2, pp.215-228.

Lin, X.W., Che, H.S. and Leung, K. (2009) 'The role of leader morality in the interaction effect of procedural justice and outcome favorability', Journal of Applied Social Psychology, Vol. 39, No. 7, pp.1536-1561.

Lomax, R.G. and Schumacker, R.E. (2004) A Beginner's Guide to Structural Equation Modeling, Psychology Press.

Lu, C-S. and Lin, C-C. (2014) 'The effects of ethical leadership and ethical climate on employee ethical behavior in the international port context', Journal of Business Ethics, Vol. 124, No. 2, pp.209-223.

Luria, G. and Yagil, D. (2008) 'Procedural justice, ethical climate and service outcomes in restaurants', International Journal of Hospitality Management, Vol. 27, No. 2, pp.276-283.

Manz, C.C., Anand, V., Joshi, M. and Manz, K.P. (2008) 'Emerging paradoxes in executive leadership: a theoretical interpretation of the tensions between corruption and virtuous values', The Leadership Quarterly, Vol. 19, No. 3, pp.385-392. 
Mayer, D.M., Kuenzi, M., Greenbaum, R., Bardes, M. and Salvador, R.B. (2009) 'How low does ethical leadership flow? Test of a trickle-down model', Organizational Behavior and Human Decision Processes, Vol. 108, No. 1, pp.1-13.

McCain, S-L.C., Tsai, H. and Bellino, N. (2010) 'Organizational justice, employees' ethical behavior, and job satisfaction in the casino industry', International Journal of Contemporary Hospitality Management, Vol. 22, No. 7, pp.992-1009.

Mehta, S.N. (2003) 'MCI: Is being good good enough?', Fortune, Vol. 148, No. 9, pp.117-117.

Mitchell, M.S., Reynolds, S.J. and Treviño, L.K. (2017) 'The study of behavioral ethics within organizations', Personnel Psychology, Vol. 70, No. 2, pp.313-314.

Moore, C., Mayer, D.M., Chiang, F.F., Crossley, C., Karlesky, M.J. and Birtch, T.A. (2019) 'Leaders matter morally: the role of ethical leadership in shaping employee moral cognition and misconduct', Journal of Applied Psychology, Vol. 104, No. 1, p.123.

Neubert, M.J., Carlson, D.S., Kacmar, K.M., Roberts, J.A. and Chonko, L.B. (2009) 'The virtuous influence of ethical leadership behavior: evidence from the field', Journal of Business Ethics, Vol. 90, No. 2, pp.157-170.

Neves, P., Almeida, P. and Velez, M.J. (2018) 'Reducing intentions to resist future change: combined effects of commitment-based HR practices and ethical leadership', Human Resource Management, Vol. 57, No. 1, pp.249-261.

Nunnally, J.C. and Bernstein, I.H. (1994) Psychometric Theory, McGraw-Hill, New York.

Ofori, G. (2009) 'Ethical leadership: examining the relationships with full range leadership model, employee outcomes, and organizational culture', Journal of Business Ethics, Vol. 90, No. 4, p.533.

Ones, D.S. and Dilchert, S. (2012) 'Environmental sustainability at work: a call to action', Industrial and Organizational Psychology, Vol. 5, No. 4, pp.444-466.

Oreg, S. (2003) 'Resistance to change: developing an individual differences measure', Journal of Applied Psychology, Vol. 88, No. 4, p.680.

Padilla, A., Hogan, R. and Kaiser, R.B. (2007) 'The toxic triangle: destructive leaders, susceptible followers, and conducive environments', The Leadership Quarterly, Vol. 18, No. 3, pp.176-194.

Podsakoff, P.M., MacKenzie, S.B. and Podsakoff, N.P. (2012) 'Sources of method bias in social science research and recommendations on how to control it', Annual Review of Psychology, Vol. 63, pp.539-569.

Podsakoff, P.M., MacKenzie, S.B., Lee, J.Y. and Podsakoff, N.P. (2003) 'Common method biases in behavioral research: a critical review of the literature and recommended remedies', Journal of Applied Psychology, Vol. 88, No. 5, p.879.

Preacher, K. and Hayes, A. (2008) 'Asymptotic and resampling strategies for assessing and comparing indirect effects in multiple mediator models', Behaviour Research Methods, Vol. 40, pp.879-891, The Sage Handbook of Advanced Data Analysis Methods for Communication Research, p.1354.

Preacher, K.J. and Hayes, A.F. (2004) 'SPSS and SAS procedures for estimating indirect effects in simple mediation models', Behavior Research Methods, Instruments, \& Computers, Vol. 36, No. 4, pp.717-731.

Ringle, C.M., Wende, S. and Becker, J-M. (2015) SmartPLS 3, SmartPLS, Bonningstedt [online] http://www.smartpls.com (accessed 30 December 2018).

Schaubroeck, J., Walumbwa, F.O., Ganster, D.C. and Kepes, S. (2007) 'Destructive leader traits and the neutralizing influence of an 'enriched' job', The Leadership Quarterly, Vol. 18, No. 3, pp.236-251.

Schminke, M., Ambrose, M.L. and Neubaum, D.O. (2005) 'The effect of leader moral development on ethical climate and employee attitudes', Organizational Behavior and Human Decision Processes, Vol. 97, No. 2, pp.135-151.

Spagat, M. (2010) 'Ethical and data-integrity problems in the second lancet survey of mortality in Iraq', Defence and Peace Economics, Vol. 21, No. 1, pp.1-41. 
Stead, W.E., Worrell, D.L. and Stead, J.G. (1990) 'An integrative model for understanding and managing ethical behavior in business organizations', Journal of Business Ethics, Vol. 9, No. 3, pp.233-242.

Steensma, H. and Visser, E. (2007) 'Procedural justice and supervisors' personal power bases: effects on employees' perceptions of performance appraisal sessions, commitment, and motivation', Journal of Collective Negotiations, Vol. 31, No. 2, pp.101-118.

Sullivan, G.M. and Feinn, R. (2012) 'Using effect size - or why the P value is not enough', Journal of Graduate Medical Education, Vol. 4, No. 3, pp.279-282.

Taştan, S.B. and Davoudi, S.M.M. (2019) 'The relationship between socially responsible leadership and organisational ethical climate: in search for the role of leader's relational transparency', International Journal of Business Governance and Ethics, Vol. 13, No. 3, pp.275-299.

Tehseen, S., Ramayah, T. and Sajilan, S. (2017) 'Testing and controlling for common method variance: a review of available methods', Journal of Management Sciences, Vol. 4, No. 2, pp.142-168.

Treviño, L.K. and Brown, M.E. (2004) 'Managing to be ethical: debunking five business ethics myths', Academy of Management Perspectives, Vol. 18, No. 2, pp.69-81.

Treviño, L.K. and Weaver, G.R. (2001) 'Organizational justice and ethics program 'follow-through': influences on employees' harmful and helpful behavior', Business Ethics Quarterly, Vol. 11, No. 4, pp.651-671.

Treviño, L.K., Butterfield, K.D. and McCabe, D.L. (1998) 'The ethical context in organizations: influences on employee attitudes and behaviors', Business Ethics Quarterly, Vol. 8, No. 3, pp.447-476.

Treviño, L.K., Den Nieuwenboer, N.A. and Kish-Gephart, J.J. (2014) '(Un) ethical behavior in organizations', Annual Review of Psychology, Vol. 65, pp.635-660.

Treviño, L.K., Hartman, L.P. and Brown, M. (2000) 'Moral person and moral manager: how executives develop a reputation for ethical leadership', California Management Review, Vol. 42, No. 4, pp.128-142.

Victor, B. and Cullen, J.B. (1988) 'The organizational bases of ethical work climates', Administrative Science Quarterly, Vol. 33, No. 1, pp.101-125.

Wetzels, M., Odekerken-Schröder, G. and Van Oppen, C. (2009) 'Using PLS path modeling for assessing hierarchical construct models: guidelines and empirical illustration', MIS Quarterly, pp.177-195.

$\mathrm{Xu}$, A.J., Loi, R. and Ngo, H-y. (2016) 'Ethical leadership behavior and employee justice perceptions: the mediating role of trust in organization', Journal of Business Ethics, Vol. 134, No. 3, pp.493-504. 